\title{
Update in Interstitial Lung Disease 2016
}

\author{
Athol U. Wells ${ }^{1}$ and Toby M. Maher ${ }^{1,2}$ \\ ${ }^{1}$ Interstitial Lung Disease Unit, Royal Brompton Hospital, London, United Kingdom; and ${ }^{2}$ Fibrosis Research Group, National Heart and \\ Lung Institute, Imperial College, London, United Kingdom
}

Entomologically, metamorphosis is defined as the process of transformation from an immature form to an adult form. No better term exists for the coming of age of interstitial lung disease (ILD) in 2014. The pivotal trials of antifibrotic agents $(1,2)$ in idiopathic pulmonary fibrosis (IPF) changed the specialty irrevocably. For the first time, the diagnostic distinction between IPF and other forms of ILD matters therapeutically. The reappraisal of risks and benefits of invasive diagnostic procedures and the emerging data on the diagnostic accuracy of high-resolution computed tomography (HRCT) in key IPF subgroups has major implications for multidisciplinary practice. The efficacy of pirfenidone and nintedanib poses new challenges in trial design. The perceived need for earlier IPF diagnosis has led to increased interest in studies of "interstitial lung abnormalities" (ILAs) in elderly patients. Acute exacerbations of IPF are under renewed scrutiny, and the surge in Internet information on IPF has created its own problems regarding misinformation. Basic science research in IPF mechanisms, already an area of rapid development, has never seemed more relevant to future clinical developments.

The changes within the ILD specialty are captured by the nature of articles published in 2016 in the Journal. IPF was either the primary focus or an important component in 15 of 21 ILD perspectives and original research articles. Sarcoidosis was the subject of two reports, and the remaining publications explored clinical and scientific issues in pulmonary fibrosis.

\section{Diagnosis}

Although surgical biopsy is no longer viewed as a diagnostic reference standard in ILD, it remains the single most informative test when clinical and HRCT features are difficult to classify. In the 2011 American Thoracic Society/European Respiratory Society/Japanese Respiratory Society/Latin American Thoracic Association guideline for the diagnosis and management of IPF, a diagnostic biopsy was viewed as essential in the large subgroup of patients likely to have IPF but lacking typical HRCT features (3). It can be argued that this recommendation did not sufficiently acknowledge contraindications to surgical lung biopsy, including age, comorbidities, and severe disease. Hutchinson and colleagues examined in-hospital mortality after surgical lung biopsy (SLB) in interstitial lung disease in the United States (4). They estimated that approximately 12,000 SLBs are performed annually in the United States, with in-hospital mortalities of 1.7 and $16.0 \%$ for elective and nonelective procedures, respectively. Risk factors for mortality comprised male sex, increasing age, increasing comorbidity, open surgery, and a provisional diagnosis of IPF or connective tissue disease (disease severity was not evaluated as a risk factor). As emphasized in a companion editorial, these data help clinicians and patients to take into account the risks related to SLB and indicate that SLB should be reserved for those patients in whom the findings are likely to have treatment implications (5).

Bronchoscopic lung cryobiopsy (BLC), a new technique developed in Europe, has the potential to provide diagnostic information at a reduced risk, compared with SLB. In two recent meta-analyses of studies performed in patients with ILD, the diagnostic yields (for a histological pattern or a multidisciplinary diagnosis) were $81 \%$ (95\% confidence interval, 75-87\%) (6) and 79\% (95\% confidence interval, 65-93\%) (7). Mortality associated with BLC was $0.3 \%$ (6), and the pneumothorax rates were $6 \%$ (6) and $12 \%$ (7). The definition of severity of bleeding was not standardized, and data on moderate to severe bleeding are difficult to interpret. A prevailing difficulty in ILD is the absence of a diagnostic reference standard against which to evaluate BLC: multidisciplinary diagnosis includes all available data, including BLC information when available. Moreover, multidisciplinary diagnosis itself is hardly a reference standard, given the significant diagnostic disagreement between expert multidisciplinary groups with evaluation of the same patient data in a recent pivotal study (8).

Important surrogate measures for accuracy in IPF diagnosis, agreement between experts and diagnostic confidence, were explored by Tomassetti and colleagues in a cross-sectional study (9). Patients with

(Received in original form February 14, 2017; accepted in final form April 19, 2017)

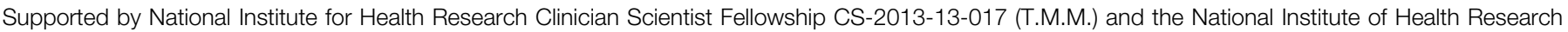

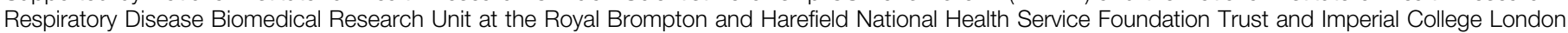
(A.U.W.).

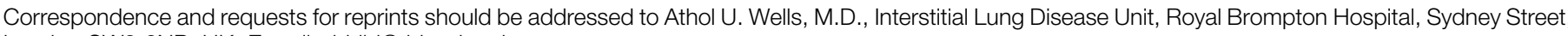
London SW3 6NP, UK. E-mail: rbhild@rbht.nhs.uk 
fibrotic interstitial lung disease without a typical usual interstitial pneumonia pattern on HRCT $(\mathrm{n}=117)$ underwent BLC $(n=58)$ or SLB $(n=59)$. On the basis of the methodology of Flaherty and colleagues (10), two clinicians, radiologists, and pathologists recorded their first-choice diagnoses and diagnostic confidence at each step of the diagnostic process. There were major and strikingly similar increases in the proportion of IPF diagnoses made with high confidence with BLC (29-63\%, $P=0.0003)$ and SLB (30-65\%, $P=0.0016)$. Diagnostic agreement between participants was similarly excellent for both procedures. The addition of histopathologic data resulted in a change in diagnosis to IPF in $17 \%$ of cases in the BLC subgroup and in $19 \%$ of cases in the SLB group. In an associated editorial, the distinction between accuracy and agreement was highlighted, but the very considerable advantages of a highly confident diagnosis were not acknowledged in this commentary (11). However, more work is required to show that the balance of yield and risk remains acceptable when BLC is used more widely, outside the expert centers that have pioneered its development.

The growing interest in the identification of subclinical IPF has been fueled by analyses showing that treatment benefits of antifibrotic agents on serial FVC trends are virtually identical above and below FVC thresholds of $70 \%, 80 \%$, and 90\% (12-14). ILAs, studied in elderly cohorts (15-20), and IPF have strikingly similar associations with advancing age, smoking status, smoking dose, and linkage to the mucin 5B (MUC5B) promoter polymorphism (21), raising the possibility that screening for ILA might facilitate the early identification of IPF. The study of Araki and colleagues of patterns of ILA progression (defined by serial HRCT and pulmonary function data) in a Framingham Heart Study cohort adds an important piece of the jigsaw (22). Intriguingly, ILA progression was linked to the MUC5B genotype and significantly increased subsequent mortality. More than $80 \%$ of ILAs in this study were reticular and subpleural. ILA progression on HRCT was associated with a decline in FVC of $64 \mathrm{ml} / \mathrm{yr}$, only $25 \mathrm{ml} / \mathrm{yr}$ higher than in subjects without ILAs and substantially lower than observed in the placebo arms of IPF trials.

The prevalence of ILAs in five cohorts, approximating $6 \%$, is an order of magnitude higher than the prevalence of IPF. Thus, it appears likely that only a minority of ILAs do, in reality, progress to IPF, and this suggests that the identification of subclinical IPF within ILA subgroups will require the integration of serum biomarker signal predictive of ILA progression (23). Although no data exist linking biomarker signal to ILA progression, this concept was indirectly supported by findings in the study of Ho and colleagues in the Framingham Heart Study cohort (24). Higher plasma galectin-3 levels were associated with the presence of ILAs, lower lung volumes, and reduced carbon monoxide diffusing capacity and, by implication, to pathogenetic events leading to the genesis of ILAs.

\section{Other Clinical Topics}

An international working group statement on acute exacerbation of IPF (AEIPF) included evidence-based updates on epidemiology, etiology, risk factors, prognosis, and management (25). AEIPF diagnostic criteria were revised to include any acute respiratory event (irrespective of the presence of an overt trigger such as infection) characterized by new widespread alveolar abnormalities on HRCT not fully explained by cardiac failure or fluid overload. The statement highlighted limitations in the evidence base, with many existing uncertainties on all aspects of AEIPF and a notable lack of data from which to construct management recommendations; the report provides a shared framework for clinicians and researchers.

Importantly, the AEIPF working group endorsed microaspiration as a potential AEIPF trigger (26-28), adding to interest in gastroesophageal reflux as a potential driver of IPF progression. In a perspective on IPF treatment with proton pump inhibitors by Ghebre and Raghu, the lack of definitive controlled data establishing that treatment benefits exist was highlighted (29), with conflicting information emerging in recent retrospective studies $(27,30)$. Nonetheless, the perspective provides a useful summary of indirect evidence suggesting a pathogenetic role for gastroesophageal reflux in a subgroup of patients with IPF.

Faisal and colleagues explored mechanisms of dyspnea in chronic interstitial and obstructive lung disease, concluding that the association between the intensity of dyspnea and inspiratory neural drive was not influenced by disease-specific aspects of mechanics and respiratory muscle activity (31). These observations underline the potential importance of the accurate quantification of dyspnea both in clinical practice and as a pivotal end point in future trials. Given a close linkage between dyspnea intensity and levels of inspiratory neural drive, patient ratings of the severity of dyspnea may provide information on the burden on the respiratory system not necessarily captured by pulmonary function abnormalities at rest (32).

The wealth of ILD data published in recent years, taken together with shifts in paradigm thinking, have led to major difficulties for patients wishing to access accurate information from the Internet. A systematic assessment of the content of the top 181 ranked websites by Fisher and colleagues revealed that information on IPF was mostly incomplete, inaccurate, and outdated when evaluated against a 16-item questionnaire and JAMA benchmarks (33).

Strikingly, websites generally failed to detail the risks of treatment but often highlighted a treatment regimen known to increase the risk of death and hospitalization, given a strong negative recommendation by American Thoracic Society/European Respiratory

Society/Japanese Respiratory Society/Latin American Thoracic Association guidelines. It has been suggested that initiatives by the Pulmonary Fibrosis Foundation to develop accurate patient information may provide a much-needed solution (34).

\section{Management and IPF Trial Design}

The advent of extracorporeal membrane oxygenation (ECMO) has created new opportunities to bridge patients with ILD with acute respiratory failure to recovery or transplantation. In a retrospective analysis of patients with ILD treated with ECMO, Trudzinski and colleagues reported that 6 of 21 patients underwent lung transplantation, with 5 able to be discharged from the hospital (35). By contrast, 14 of 15 patients not undergoing transplantation (including 2 patients on the transplantation waiting list) died after $40.3 \pm 27.8$ days on ECMO. The authors concluded that ECMO is a lifesaving option in bridging to lung 
transplantation but offers no prognostic advantages in the remaining patients with ILD with acute respiratory failure, a view that was endorsed in a commentary on the study (36). It is important to stress the distinction between acute respiratory failure in preexisting fibrotic ILD, presumably the starting point in this report, and de novo acute ILD processes with a greater potential for eventual recovery; these findings should not be extrapolated to the latter scenario.

The IPF trial database continues to provide important insights both on the best clinical use of antifibrotic therapies and on study design. Costabel and colleagues conducted prespecified analyses in two replicate trials of nintedanib in IPF, establishing that nintedanib provides therapeutic benefits to a broad range of IPF phenotypes, especially including subgroups defined by age and the severity of baseline impairment in FVC levels (14). The equivalent treatment benefits, above and below FVC thresholds of $70 \%$, held true with alternative $\mathrm{FVC}$ thresholds of $80 \%$ with pirfenidone (13) and $90 \%$ with nintedanib (12). Thus, decisions by some regulatory bodies to reimburse funding for antifibrotic therapy only in patients with IPF with FVC levels below $80 \%$ are not based on existing evidence and are clearly driven by other considerations (37). Further important findings were that in patients with more severe disease (FVC $<70 \%$ ), nintedanib maintains health-related quality of life and may reduce the risk of AEIPF, although the latter observation was underpowered (due to the low number of AEIPF events).

Most prognostic analyses in IPF have focused on mortality prediction and, to a lesser extent, on respiratory hospitalization. Prediction of chronic disease progression, quantified using serial FVC trends, has been less studied. The accurate identification of patients with IPF with more progressive disease would have obvious advantages for clinical decision-making as well as improving the efficiency of clinical trials by allowing "cohort enrichment" (i.e., the selective enrollment of patients in whom a treatment benefit can be identified more definitively). In an analysis of two trials of pirfenidone in IPF, Ley and colleagues evaluated baseline and past-change variables against chronic disease progression, defined using 48-week FVC, dyspnea, and 6-minute-walk distance trends (38). The findings were disappointing but definitive. Measures of chronic disease progression were not meaningfully predicted by the top-performing predicted models, whereas models for time to respiratory hospitalization or death achieved a satisfactory level of accuracy. Perhaps the most important message from this study is that attempts to identify likely disease progression from clinical variables are highly unlikely to be fruitful without the integration of genetic and biomarker data (39).

\section{Home Spirometry}

With the advent of wearable technology, there has been an explosion in interest in monitoring chronic disease within the domiciliary setting to improve delivery of care and to identify, at an early stage, acute deteriorations. FVC has become the accepted standard for assessing disease progression in IPF. Domiciliary monitoring of spirometry is currently routine in many transplant centers around the world. With this in mind, Russell and colleagues sought to explore the feasibility of measuring daily FVC in 50 individuals with IPF using a hand-held spirometer (40). The authors were able to demonstrate that home FVC could be practicably and reliably measured in the majority of subjects. Furthermore, the data generated were highly informative, identifying within 3 months a group of patients at high risk of short-term mortality; subjects losing more than 5\% FVC over 3 months had a median survival of 334 days compared with a median survival of 930 days in those with a slower rate of decline. In addition, in four cases, home spirometry effectively identified acute exacerbations of disease. Although not yet ready for routine clinical practice, home spirometry has the potential to inform shorter proof-of-concept trials as well as be used as a tool for detecting acute worsening of disease $(41,42)$.

\section{Precision Medicine and Biomarkers}

Precision medicine, as defined by the National Institutes of Health's Precision Medicine Initiative Working Group, is an approach to disease treatment and prevention that seeks to maximize therapeutic effectiveness by taking into account individual genetic, molecular, environmental, and lifestyle differences. As discussed in depth by Brownell and colleagues in an insightful Concise Clinical Review, precision medicine represents a new frontier for IPF clinical research that provides an opportunity to integrate mechanistic, pathobiological, environmental, and behavioral approaches to disease classification and treatment (43).

Biomarkers to aid diagnosis, identify disease subgroups, and determine disease progression and response to therapy are vital tools required to effectively deliver precision medicine (44). White and colleagues have therefore made an important contribution to our understanding of the diagnostic value of a range of previously identified fibrosis biomarkers (45). The researchers used an existing multiplex platform, the fibroplex, to measure 35 fibrosis-associated proteins in the plasma of healthy control subjects and individuals with IPF and a range of other interstitial lung disorders.

Their data revealed osteopontin, matrix metalloproteinase-7, and surfactant protein-D to be the proteins with the greatest discriminatory power when seeking to separate IPF from other nonIPF interstitial lung diseases. In a validation cohort including subjects with rheumatoid arthritis-usual interstitial pneumonia, the authors found an overlapping biomarker signature between IPF and the rheumatoid arthritis-usual interstitial pneumonia group, suggesting that their three-biomarker signature might better be considered an identifier of progressive fibrosis rather than IPF alone. Validation is required in further prospective cohorts before these observations can be translated in to routine clinical practice (46).

Pennathur and colleagues combined the identification of potential diagnostic biomarkers with mechanistic studies to highlight novel pathogenic mechanisms (47). The authors demonstrated that three tyrosine-oxidation products, all markers of heightened oxidative stress responses, are elevated in the plasma of individuals with interstitial lung disease compared with healthy control subjects. They were able to demonstrate a similar increase occurring in the murine bleomycin model. In vitro experiments suggest that these tyrosine oxidation products are generated by the action of a heme peroxidase, most likely myeloperoxidase, released by activated neutrophils and macrophages and 
transforming growth factor- $\beta$-stimulated myofibroblasts. This study confirms that biomarkers of oxidative stress might be feasibly measured in interstitial lung diseases and that they may provide clinically informative and disease-relevant information (48). Prospective longitudinal biomarker studies are, however, required to validate these findings.

\section{IPF Pathogenesis}

Since the initial reclassification of the idiopathic interstitial pneumonias in 2001, there has been an exponential improvement in understanding of the key pathogenic mechanisms involved in the development and progression of IPF. It is now apparent that IPF is a disease characterized by aberrant activation of wound-healing pathways that occurs after repeated injury and premature aging of alveolar epithelial cells in genetically susceptible individuals (49). These insights have been further developed during 2016. The most robust genetic linkage to IPF susceptibility is with a polymorphism in the gene for MUC5B. The role played by MUC5B in the pathogenesis of IPF remains to be defined. Early work published in 2016 demonstrates that MUC5B is present in bronchial epithelial cells and hyperplastic epithelial cells lining honeycomb airspaces in IPF but not in the fibrotic regions of scleroderma-associated NSIP (50). In vitro in airway epithelial cells, the IPF-related promoter polymorphism results in increased secretion of MUC5B compared with the wild-type allele (51).

TGF- $\beta$ is the prototypic profibrotic growth factor that is believed to play a central role in the development of fibrosis in IPF. The functions of TGF- $\beta$ are well understood. What is less clear in IPF are the sources of excess TGF- $\beta$ and, equally importantly, what factors lead to activation of the latent form of the growth factor. Froese and colleagues demonstrate an important role for mechanical lung stretch in activating TGF- $\beta$ in fibrotic but not healthy lung (52). The group used rat lungs induced to undergo fibrosis by TGF- $\beta$ overexpression and showed ex vivo in a tissue bath that mechanical stretch of fibrotic lung tissues results in TGF- $\beta$ activation with consequent phosphorylation of Smad 2/3. Normal lung tissue fails to show any such response. Importantly, the group was able to replicate these findings in human fibrotic lung samples. The role of dynamic lung stretch, which occurs as a direct consequence of breathing, is frequently and erroneously overlooked in pathogenic studies. This study also goes some way to explain why mechanical ventilation can prove to be deleterious in patients with fibrotic lung disease through the triggering of acute exacerbations (53).

Matriptase, a transmembrane serine protease, is known to proteolytically cleave protease-activated receptor-2, a G-coupled receptor implicated in the development of fibrosis. Bardou and colleagues demonstrate that matriptase is up-regulated in IPF lung (54). In murine bleomycin experiments, matriptase is up-regulated during fibrogenesis, whereas treatment of mice with the matriptase inhibitor camostat mesilate attenuates the development of fibrosis. In in vitro experiments, matriptase was shown to stimulate fibroproliferative responses in lung fibroblasts, an effect strongly attenuated by protease-activated receptor- 2 inhibition. As well as shedding light on a hitherto unrecognized pathogenic mechanism, this study highlights a potential novel treatment approach through inhibition of matriptase by camostat mesilate, a drug that has been used in Japan as a treatment for chronic pancreatitis (55).

Another pathogenic insight with the potential to lead to novel therapeutic developments is that reported by Tan and colleagues relating to relaxin/insulin-like family peptide (56). The authors observed that relaxin/insulin-like family peptide-1 gene expression is decreased in the lungs of individuals with IPF. In in vitro experiments, treatment of fibroblasts with a relaxin-like peptide, CGEN25009, reduces collagen production. In vivo in murine bleomycin models, the same peptide abrogates fibrosis. Although these data suggest a potential role for relaxin augmentation in the treatment of pulmonary fibrosis, it is important to highlight that recombinant human relaxin has proved ineffective in randomized clinical trials performed in subjects with diffuse cutaneous scleroderma (57).

Desmoplakin, a dermosomal cell-cell adhesion protein, is important in wound healing and epithelial barrier function. Mathai and colleagues, building on previous seminal work from their group $(58,59)$, sought to identify biologically relevant sequence variants in the desmoplakin gene associated with IPF (60). To do so, they sequenced a locus on chromosome 6 in 230 subjects with IPF and 228 control subjects. The authors report two sequence variants that modify risk of developing IPF: rs2744371 a noncoding variant in intron 1 was protective against IPF, whereas a previously described IPF-associated intron 5 variant, rs2076295, was associated with increased risk. Interestingly, the authors found that desmoplakin was increased in IPF lung tissue, and immunohistochemical staining localized desmoplakin to the bronchial epithelium.

These data challenge the concept that IPF is a disease driven primarily by abnormalities in the alveolar epithelium (61).

Although the epithelium seems likely to be the site of initiation for IPF, the fibroblast and its activated form, the myofibroblast, remain the key effector cells responsible for the production of extracellular matrix in the fibrotic lung (62). With this in mind,

Tzouvelekis and colleagues studied the role of $\mathrm{H} 2$ domain-containing tyrosine phosphatase-2 (SHP2), a ubiquitously expressed nonreceptor protein tyrosine phosphatase, in driving the profibrotic phenotype of IPF lung fibroblasts (63). In studies with IPF lung tissue, the authors found down-regulation of SHP2 within fibrotic regions. In vitro, they were able to demonstrate that SHP2 knockdown increased fibroblast-to-myofibroblast transformation. In vivo, in murine bleomycin lung fibrosis, inhibition of SHP2 increased fibrosis, and this was blocked by lung-targeted lentiviral delivery of SHP2. These data suggest that SHP2 augmentation represents a potential therapeutic strategy in IPF.

COPD and IPF may represent opposite ends of an aberrant wound-healing response to repeated injury. In the case of COPD, repair mechanisms are inadequate and fail to replace damaged alveoli, whereas in IPF, the injury response results in exaggerated and uncontrolled extracellular matrix production and scarring. The overlap between these two disorders has been given the name combined pulmonary fibrosis emphysema. Kusko and colleagues explored the pathogenetic relationships between COPD and IPF in a comparative study of whole-lung transcriptomics. In so doing, they demonstrated shared transcriptional signatures between the two disorders focused around the p53/hypoxia pathways. The authors postulate that their findings demonstrate that both 
diseases share key abnormal responses to environmental stressors (64).

\section{Sarcoidosis}

Sarcoidosis remains an enigmatic and relatively poorly understood condition. Research funding for sarcoidosis has, sadly, been lagging behind that of other respiratory disorders, despite the fact that the disease causes significant morbidity and appreciable mortality in a working-age population. Nonetheless, 2016 saw the publication of two important sarcoidosis papers in the Journal. The first of these, by Rivera and colleagues, used high-density genetic mapping in five independent cohorts (four of white European descent and one of black African descent) to explore the genetic architecture of Lofgren syndrome (LS) and non-LS sarcoidosis (65). The authors identified 175 loci associated with LS and 11 loci associated with non-LS; of these loci, 5 were common between the phenotypes. Although requiring further detailed mechanistic studies, these data strongly suggest that LS and non-LS sarcoidosis are driven by distinct, albeit slightly overlapping, molecular pathways (66).

IFN- $\gamma$-producing $\mathrm{CD}^{+}{ }^{+} \mathrm{T}$-helper cells are believed to play a key role in granuloma formation in sarcoidosis. Th17.1 cells are a recently recognized subgroup of $\mathrm{CD} 4^{+}$ $\mathrm{T}$ cells that have been identified as major producers of IFN- $\gamma$ in Crohn disease. Using flow cytometry-based cell-surface marker identification and single-cell sorting, Ramstein and colleagues were able to isolate Th17.1 cells from the lavage of subjects with sarcoidosis (67). The researchers found that these Th17.1 cells, but not Th1 or Th17, were increased in the lungs of subjects with sarcoid compared with healthy control subjects. In blood, this pattern was reversed. Approximately 60\% of the isolated TH17.1 cells produced IFN$\gamma$, suggesting an important role for these cells in the development of sarcoidosis and thus challenging the existing paradigm that sarcoidosis is a Th1-driven disease. This is an insight that may turn out to have important therapeutic consequences, especially given the fact that TH17.1 cells are generally considered to be relatively insensitive to corticosteroids (68).

\section{Conclusions}

The availability of effective antifibrotic therapies has provided additional impetus to the clinical and basic science study of fibrosing lung disease. The growing body of preclinical literature is shining an everbrighter light on the key mechanisms involved in the development of IPF, to the extent that the moniker "idiopathic" now urgently requires revision. In the clinical domain, the role of both existing and new technologies (such as cryobiopsy and novel blood biomarkers) in diagnosing and monitoring fibrosing lung disease has been better defined. In addition, the patient voice is, very rightly, growing stronger, and the importance of high-quality sources of information in facilitating this cannot be overemphasized. Looking to the future, although there remain many questions to be answered, it is to be hoped that the recent giant strides made in fibrosing lung disease will be replicated in other interstitial lung diseases, such as sarcoidosis.

Author disclosures are available with the text of this article at www.atsjournals.org.

\section{References}

1. Richeldi L, du Bois RM, Raghu G, Azuma A, Brown KK, Costabel U, Cottin V, Flaherty KR, Hansell DM, Inoue Y, et al.; INPULSIS Trial Investigators. Efficacy and safety of nintedanib in idiopathic pulmonary fibrosis. N Engl J Med 2014;370:2071-2082.

2. King TE Jr, Bradford WZ, Castro-Bernardini S, Fagan EA, Glaspole I, Glassberg MK, Gorina E, Hopkins PM, Kardatzke D, Lancaster L, et al.; ASCEND Study Group. A phase 3 trial of pirfenidone in patients with idiopathic pulmonary fibrosis. N Engl J Med 2014;370: 2083-2092.

3. Raghu G, Collard HR, Egan JJ, Martinez FJ, Behr J, Brown KK, Colby TV, Cordier JF, Flaherty KR, Lasky JA, et al.; ATS/ERS/JRS/ALAT Committee on Idiopathic Pulmonary Fibrosis. An official ATS/ERS/JRS/ALAT statement: idiopathic pulmonary fibrosis: evidence-based guidelines for diagnosis and management. Am J Respir Crit Care Med 2011;183:788-824.

4. Hutchinson JP, Fogarty AW, McKeever TM, Hubbard RB. In-hospital mortality after surgical lung biopsy for interstitial lung disease in the United States. 2000 to 2011. Am J Respir Crit Care Med 2016;193: 1161-1167.

5. Raj R, Brown KK. Mortality related to surgical lung biopsy in patients with interstitial lung disease: the devil is in the denominator. $A m \mathrm{~J}$ Respir Crit Care Med 2016;193:1082-1084.

6. Ravaglia C, Bonifazi M, Wells AU, Tomassetti S, Gurioli C, Piciucchi S, Dubini A, Tantalocco P, Sanna S, Negri E, et al. Safety and diagnostic yield of transbronchial lung cryobiopsy in diffuse parenchymal lung diseases: a comparative study versus video-assisted thoracoscopic lung biopsy and a systematic review of the literature. Respiration 2016;91:215-227.

7. Johannson KA, Marcoux VS, Ronksley PE, Ryerson CJ. Diagnostic yield and complications of transbronchial lung cryobiopsy for interstitial lung disease: a systematic review and metaanalysis. Ann Am Thorac Soc $2016 ; 13: 1828-1838$.
8. Walsh SL, Wells AU, Desai SR, Poletti V, Piciucchi S, Dubini A, Nunes H, Valeyre D, Brillet PY, Kambouchner M, et al. Multicentre evaluation of multidisciplinary team meeting agreement on diagnosis in diffuse parenchymal lung disease: a case-cohort study. Lancet Respir Med 2016;4:557-565.

9. Tomassetti S, Wells AU, Costabel U, Cavazza A, Colby TV, Rossi G, Sverzellati N, Carloni A, Carretta E, Buccioli M, et al. Bronchoscopic lung cryobiopsy increases diagnostic confidence in the multidisciplinary diagnosis of idiopathic pulmonary fibrosis. Am J Respir Crit Care Med 2016;193:745-752.

10. Flaherty KR, King TE Jr, Raghu G, Lynch JP III, Colby TV, Travis WD, Gross BH, Kazerooni EA, Toews GB, Long Q, et al. Idiopathic interstitial pneumonia: what is the effect of a multidisciplinary approach to diagnosis? Am J Respir Crit Care Med 2004;170: 904-910.

11. Patel NM, Borczuk AC, Lederer DJ. Cryobiopsy in the diagnosis of interstitial lung disease: a step forward or back? Am J Respir Crit Care Med 2016;193:707-709.

12. Kolb M, Richeldi L, Behr J, Maher TM, Tang W, Stowasser S, Hallmann $\mathrm{C}$, du Bois RM. Nintedanib in patients with idiopathic pulmonary fibrosis and preserved lung volume. Thorax 2017;72:340-346.

13. Albera C, Costabel U, Fagan EA, Glassberg MK, Gorina E, Lancaster L, Lederer DJ, Nathan SD, Spirig D, Swigris JJ. Efficacy of pirfenidone in patients with idiopathic pulmonary fibrosis with more preserved lung function. Eur Respir J 2016;48:843-851.

14. Costabel U, Inoue Y, Richeldi L, Collard HR, Tschoepe I, Stowasser S, Azuma A. Efficacy of nintedanib in idiopathic pulmonary fibrosis across prespecified subgroups in INPULSIS. Am J Respir Crit Care Med 2016;193:178-185.

15. Lederer DJ, Enright PL, Kawut SM, Hoffman EA, Hunninghake G, van Beek EJ, Austin JH, Jiang R, Lovasi GS, Barr RG. Cigarette smoking is associated with subclinical parenchymal lung disease: the MultiEthnic Study of Atherosclerosis (MESA)-lung study. Am J Respir Crit Care Med 2009;180:407-414. 
16. Washko GR, Lynch DA, Matsuoka S, Ross JC, Umeoka S, Diaz A, Sciurba FC, Hunninghake GM, San José Estépar R, Silverman EK, et al. Identification of early interstitial lung disease in smokers from the COPDGene Study. Acad Radiol 2010;17:48-53.

17. Washko GR, Hunninghake GM, Fernandez IE, Nishino M, Okajima Y, Yamashiro T, Ross JC, Estépar RS, Lynch DA, Brehm JM, et al.; COPDGene Investigators. Lung volumes and emphysema in smokers with interstitial lung abnormalities. N Engl J Med 2011;364:897-906.

18. Doyle TJ, Washko GR, Fernandez IE, Nishino M, Okajima Y, Yamashiro T, Divo MJ, Celli BR, Sciurba FC, Silverman EK, et al.; COPDGene Investigators. Interstitial lung abnormalities and reduced exercise capacity. Am J Respir Crit Care Med 2012;185: 756-762.

19. Jin GY, Lynch D, Chawla A, Garg K, Tammemagi MC, Sahin H, Misumi $\mathrm{S}$, Kwon KS. Interstitial lung abnormalities in a CT lung cancer screening population: prevalence and progression rate. Radiology 2013;268:563-571.

20. Putman RK, Hatabu H, Araki T, Gudmundsson G, Gao W, Nishino M, Okajima Y, Dupuis J, Latourelle JC, Cho MH, et al.; Evaluation of COPD Longitudinally to Identify Predictive Surrogate Endpoints (ECLIPSE) Investigators; COPDGene Investigators. Association between interstitial lung abnormalities and all-cause mortality. JAMA 2016;315:672-681.

21. Hunninghake GM, Hatabu H, Okajima Y, Gao W, Dupuis J, Latourelle JC, Nishino M, Araki T, Zazueta OE, Kurugol S, et al. MUC5B promoter polymorphism and interstitial lung abnormalities. $N$ Engl $J$ Med 2013;368:2192-2200.

22. Araki T, Putman RK, Hatabu H, Gao W, Dupuis J, Latourelle JC, Nishino M, Zazueta OE, Kurugol S, Ross JC, et al. Development and progression of interstitial lung abnormalities in the Framingham Heart Study. Am J Respir Crit Care Med 2016;194: 1514-1522.

23. Wells AU, Kokosi MA. Subclinical interstitial lung abnormalities: toward the early detection of idiopathic pulmonary fibrosis? Am J Respir Crit Care Med 2016;194:1445-1446.

24. Ho JE, Gao W, Levy D, Santhanakrishnan R, Araki T, Rosas IO, Hatabu $\mathrm{H}$, Latourelle JC, Nishino M, Dupuis J, et al. Galectin-3 is associated with restrictive lung disease and interstitial lung abnormalities. $A m \mathrm{~J}$ Respir Crit Care Med 2016;194:77-83.

25. Collard HR, Ryerson CJ, Corte TJ, Jenkins G, Kondoh Y, Lederer DJ, Lee JS, Maher TM, Wells AU, Antoniou KM, et al. Acute exacerbation of idiopathic pulmonary fibrosis: an international working group report. Am J Respir Crit Care Med 2016;194:265-275.

26. Tcherakian C, Cottin V, Brillet PY, Freynet O, Naggara N, Carton Z, Cordier JF, Brauner M, Valeyre D, Nunes H. Progression of idiopathic pulmonary fibrosis: lessons from asymmetrical disease. Thorax 2011;66:226-231.

27. Lee JS, Collard HR, Anstrom KJ, Martinez FJ, Noth I, Roberts RS, Yow E, Raghu G,; IPFnet Investigators. Anti-acid treatment and disease progression in idiopathic pulmonary fibrosis: an analysis of data from three randomised controlled trials. Lancet Respir Med 2013;1:369-376.

28. Lee JS, Song JW, Wolters PJ, Elicker BM, King TE Jr, Kim DS, Collard HR. Bronchoalveolar, lavage pepsin in acute exacerbation of idiopathic pulmonary fibrosis. Eur Respir J 2012;39:352-358.

29. Ghebre YT, Raghu G. Idiopathic pulmonary fibrosis: novel concepts of proton pump inhibitors as antifibrotic drugs. Am J Respir Crit Care Med 2016;193:1345-1352.

30. Kreuter M, Wuyts W, Renzoni E, Koschel D, Maher TM, Kolb M, Weycker D, Spagnolo P, Kirchgaessler KU, Herth FJ, et al. Antacid therapy and disease outcomes in idiopathic pulmonary fibrosis: a pooled analysis. Lancet Respir Med 2016;4:381-389.

31. Faisal A, Alghamdi BJ, Ciavaglia CE, Elbehairy AF, Webb KA, Ora J, Neder JA, O'Donnell DE. Common mechanisms of dyspnea in chronic interstitial and obstructive lung disorders. Am J Respir Crit Care Med 2016;193:299-309.

32. Jolley CJ, Moxham J. Dyspnea intensity: a patient-reported measure of respiratory drive and disease severity. Am J Respir Crit Care Med 2016;193:236-238.

33. Fisher JH, O'Connor D, Flexman AM, Shapera S, Ryerson CJ. Accuracy and reliability of Internet resources for information on idiopathic pulmonary fibrosis. Am J Respir Crit Care Med 2016;194:218-225.
34. Lederer DJ, Swigris JJ. Idiopathic pulmonary fibrosis on the Internet: let's calm the sea of (mis)information. Am J Respir Crit Care Med 2016;194:134-136.

35. Trudzinski FC, Kaestner F, Schäfers HJ, Fähndrich S, Seiler F, Böhme $\mathrm{P}$, Linn O, Kaiser R, Haake H, Langer F, et al. Outcome of patients with interstitial lung disease treated with extracorporeal membrane oxygenation for acute respiratory failure. Am J Respir Crit Care Med 2016;193:527-533.

36. Moerer O, Quintel M. Bridge or abyss: extracorporeal membrane oxygenation for acute respiratory failure in interstitial lung disease. Am J Respir Crit Care Med 2016;193:474-476.

37. Wells AU, Rosas IO. Broad therapeutic efficacy of nintedanib in idiopathic pulmonary fibrosis. Am J Respir Crit Care Med 2016;193:112-113.

38. Ley B, Bradford WZ, Vittinghoff E, Weycker D, du Bois RM, Collard HR. Predictors of mortality poorly predict common measures of disease progression in idiopathic pulmonary fibrosis. Am J Respir Crit Care Med 2016;194:711-718.

39. Murray S, Flaherty KR. Clinical trial design based on time to death/progression. Am J Respir Crit Care Med 2016;194:653-654.

40. Russell AM, Adamali H, Molyneaux PL, Lukey PT, Marshall RP, Renzoni EA, Wells AU, Maher TM. Daily home spirometry: an effective tool for detecting progression in idiopathic pulmonary fibrosis. Am J Respir Crit Care Med 2016;194:989-997.

41. Wuyts WA, Spagnolo P, Bonella F, Yserbyt J, Verleden GM. Daily home spirometry: a new milestone in the field of pulmonary fibrosis. $A m \mathrm{~J}$ Respir Crit Care Med 2016;194:1033-1034.

42. Johannson KA, Ryerson CJ. What gets measured gets managed: daily home spirometry in idiopathic pulmonary fibrosis. Am J Respir Crit Care Med 2016;194:926-927.

43. Brownell R, Kaminski N, Woodruff PG, Bradford WZ, Richeldi L, Martinez FJ, Collard HR. Precision medicine: the new frontier in idiopathic pulmonary fibrosis. Am J Respir Crit Care Med 2016;193: 1213-1218.

44. Maher TM. Precision medicine in idiopathic pulmonary fibrosis. QJM 2016;109:585-587.

45. White ES, Xia M, Murray S, Dyal R, Flaherty CM, Flaherty KR, Moore BB, Cheng L, Doyle TJ, Villalba J, et al. Plasma surfactant protein-D, matrix metalloproteinase-7, and osteopontin index distinguishes idiopathic pulmonary fibrosis from other idiopathic interstitial pneumonias. Am J Respir Crit Care Med 2016;194:1242-1251.

46. Maher TM. Blood-based diagnosis of idiopathic pulmonary fibrosis: fantasy or reality? Am J Respir Crit Care Med 2016;194:1182-1184.

47. Pennathur S, Vivekanandan-Giri A, Locy ML, Kulkarni T, Zhi D, Zeng L, Byun J, de Andrade JA, Thannickal VJ. Oxidative modifications of protein tyrosyl residues are increased in plasma of human subjects with interstitial lung disease. Am J Respir Crit Care Med 2016;193: 861-868.

48. Jenkins RG. To suppress the radicals we must have biomarkers of oxidative stress. Am J Respir Crit Care Med 2016;193:817-819.

49. Daccord C, Maher TM. Recent advances in understanding idiopathic pulmonary fibrosis. F1000 Res 2016;5:5.

50. Conti C, Montero-Fernandez A, Borg E, Osadolor T, Viola P, De Lauretis A, Stock CJ, Bonifazi M, Bonini M, Caramori G, et al. Mucins MUC5B and MUC5AC in distal airways and honeycomb spaces: comparison among idiopathic pulmonary fibrosis/usual interstitial pneumonia, fibrotic nonspecific interstitial pneumonitis, and control lungs. Am J Respir Crit Care Med 2016;193:462-464.

51. Nakano Y, Yang IV, Walts AD, Watson AM, Helling BA, Fletcher AA, Lara AR, Schwarz MI, Evans CM, Schwartz DA. MUC5B promoter variant rs35705950 affects MUC5B expression in the distal airways in idiopathic pulmonary fibrosis. Am J Respir Crit Care Med 2016; 193:464-466.

52. Froese AR, Shimbori C, Bellaye PS, Inman M, Obex S, Fatima S, Jenkins G, Gauldie J, Ask K, Kolb M. Stretch-induced activation of transforming growth factor- $\beta 1$ in pulmonary fibrosis. Am J Respir Crit Care Med 2016;194:84-96.

53. Hinz B, Suki B. Does breathing amplify fibrosis? Am J Respir Crit Care Med 2016;194:9-11.

54. Bardou O, Menou A, François $C$, Duitman JW, von der Thüsen JH, Borie R, Sales KU, Mutze K, Castier Y, Sage E, et al. Membraneanchored serine protease matriptase is a trigger of pulmonary fibrogenesis. Am J Respir Crit Care Med 2016;193:847-860. 
55. Sisson TH, Spagnolo P. Matriptase, protease-activated receptor 2, and idiopathic pulmonary fibrosis: further evidence for signaling pathway redundancy in this difficult-to-treat disease? Am J Respir Crit Care Med 2016;193:816-817.

56. Tan J, Tedrow JR, Dutta JA, Juan-Guardela B, Nouraie M, Chu Y, Trejo Bittar H, Ramani K, Biswas PS, Veraldi KL, et al. Expression of RXFP1 is decreased in idiopathic pulmonary fibrosis: implications for relaxin-based therapies. Am J Respir Crit Care Med 2016;194: 1392-1402.

57. Hambly N, Kolb M. Pathways to precision medicine in idiopathic pulmonary fibrosis: time to relax? Am J Respir Crit Care Med 2016; 194:1315-1317.

58. Fingerlin TE, Zhang W, Yang IV, Ainsworth HC, Russell PH, Blumhagen RZ, Schwarz MI, Brown KK, Steele MP, Loyd JE, et al. Genome-wide imputation study identifies novel HLA locus for pulmonary fibrosis and potential role for auto-immunity in fibrotic idiopathic interstitial pneumonia. BMC Genet 2016;17:74.

59. Fingerlin TE, Murphy E, Zhang W, Peljto AL, Brown KK, Steele MP, Loyd JE, Cosgrove GP, Lynch D, Groshong S, et al. Genome-wide association study identifies multiple susceptibility loci for pulmonary fibrosis. Nat Genet 2013;45:613-620.

60. Mathai SK, Pedersen BS, Smith K, Russell P, Schwarz MI, Brown KK Steele MP, Loyd JE, Crapo JD, Silverman EK, et al. Desmoplakin variants are associated with idiopathic pulmonary fibrosis. Am J Respir Crit Care Med 2016;193:1151-1160.

61. Ryu C, Homer RJ, Herzog EL. The airway in idiopathic pulmonary fibrosis: protecting the lung or promoting disease? Am J Respir Crit Care Med 2016;193:1081-1082.
62. Liang J, Zhang Y, Xie T, Liu N, Chen H, Geng Y, Kurkciyan A, Mena JM, Stripp BR, Jiang D, et al. Hyaluronan and TLR4 promote surfactantprotein-C-positive alveolar progenitor cell renewal and prevent severe pulmonary fibrosis in mice. Nat Med 2016;22:1285-1293.

63. Tzouvelekis A, Yu G, Lacks Lino Cardenas C, Herazo-Maya JD, Wang $\mathrm{R}$, Woolard T, Zhang Y, Sakamoto K, Lee H, Yi JS, et al. SH2 domain-containing phosphatase is a novel antifibrotic regulator in pulmonary fibrosis. Am J Respir Crit Care Med 2017;195:500-514.

64. Kusko RL, Brothers JF II, Tedrow J, Pandit K, Huleihel L, Perdomo C Liu G, Juan-Guardela B, Kass D, Zhang S, et al. Integrated genomics reveals convergent transcriptomic networks underlying chronic obstructive pulmonary disease and idiopathic pulmonary fibrosis. Am J Respir Crit Care Med 2016;194:948-960.

65. Rivera NV, Ronninger M, Shchetynsky K, Franke A, Nöthen MM, MüllerQuernheim J, Schreiber S, Adrianto I, Karakaya B, van Moorsel $\mathrm{CH}$, et al. High-density genetic mapping identifies new susceptibility variants in sarcoidosis phenotypes and shows genomic-driven phenotypic differences. Am J Respir Crit Care Med 2016;193:1008-1022.

66. Millar A. Two faces of sarcoidosis: a genetic insight? Am J Respir Crit Care Med 2016;193:942-943.

67. Ramstein J, Broos CE, Simpson LJ, Ansel KM, Sun SA, Ho ME, Woodruff PG, Bhakta NR, Christian L, Nguyen CP, et al. IFN$\gamma$-producing T-helper 17.1 cells are increased in sarcoidosis and are more prevalent than T-helper type 1 cells. Am J Respir Crit Care Med 2016;193:1281-1291.

68. Georas SN, Chapman TJ, Crouser ED. Sarcoidosis and T-helper cells. Th1, Th17, or Th17.1? Am J Respir Crit Care Med 2016;193: $1198-1200$. 